Pp. 1-5

DOI: $10.1089 / \mathrm{gtmb} .2014 .0236$

\title{
Detection of Turner Syndrome by Quantitative PCR of SHOX and VAMP7 Genes
}

\author{
Marisol Ibarra-Ramírez, Michelle de Jesús Zamudio-Osuna, Luis Daniel Campos-Acevedo,' \\ Hugo Leonid Gallardo-Blanco,' Ricardo Martin Cerda-Flores, \\ Irám Pablo Rodríguez-Sánchez, and Laura Elia Martínez-de-Villarreal ${ }^{1}$
}

Turner Syndrome (TS) is an unfavorable genetic condition with a prevalence of 1:2500 in newborn girls. Prompt and effective diagnosis is very important to appropriately monitor the comorbidities. The aim of the present study was to propose a feasible and practical molecular diagnostic tool for newborn screening by quantifying the gene dosage of the SHOX, VAMP7, XIST, UBAI, and SRY genes by quantitative polymerase chain reaction (qPCR) in individuals with a diagnosis of complete $\mathrm{X}$ monosomy, as well as those with TS variants, and then compare the results to controls without chromosomal abnormalities. According to our results, the most useful markers for these chromosomal variants were the genes found in the pseudoautosomic regions 1 and 2 (PAR1 and PAR2), because differences in gene dosage (relative quantification) between groups were more evident in SHOX and VAMP7 gene expression. Therefore, we conclude that these markers are useful for early detection in aneuploidies involving sex chromosomes.

\section{Introduction}

$\mathbf{T}$ URNER SYNDROME (TS) AFFECTS 1 in 2500/3000 liveborn girls and is characterized by short stature, gonadal dysgenesis, pterygium colli, cubitus valgus, and a low hairline (Wiedemann and Glatzl, 1991; Ranke and Saenger, 2001; Pinsker, 2012). It is caused by partial or total loss of the second sex chromosome (Ford et al., 1959; Sybert and McCauley, 2004). Complete monosomy X $(45, X)$ represents $50-60 \%$ of all cases, while mosaics of two or more cell lines and structural aberrations (mostly Xq isochromosomes) account for the remaining 40-50\% (Sybert and McCauley, 2004).

The $\mathrm{X}$ chromosome has 155 megabase pairs $(\mathrm{Mb})$ and contains $\sim 1000$ genes (Bianchi et al., 2012), while the Y chromosome $(60 \mathrm{Mb})$ contains only 104 protein-coding sequences out of a total of over 200 genes (Li et al., 2008). Inactivation of the majority of one $\mathrm{X}$ chromosome in females leads to a functional $1 \mathrm{n}$ dosage of $\mathrm{X}$-linked genes in both genders. The pseudoautosomal regions (PAR) 1 and 2 homologous sequences, which are present on both the $\mathrm{X}$ and $\mathrm{Y}$ chromosomes, escape from $\mathrm{X}$ chromosome inactivation. Therefore, the 24 genes present in the $2.6 \mathrm{Mb}$ PAR1 (Mangs and Morris, 2007) and the 4 genes in the $320 \mathrm{~kb}$ PAR2 have a functional gene dosage of $2 \mathrm{n}$ in both genders. Hence, the etiology of TS lies in the haploinsufficiency of genes located in the PAR1 (Zhong and Layman, 2012).
Guidelines of the American College of Endocrinology for the management of patients with TS emphasize the benefit of early detection through newborn screening methods (Bondy et al., 2007). However, only $20-30 \%$ of TS patients are diagnosed during the first year of life and another 25\% are diagnosed in adulthood (Massa et al., 2005; Stochholm et al., 2006). In Mexico, less than $15 \%$ are diagnosed during the first year of life. Early detection allows identification of malformations of the cardiovascular system and prevention or management of short stature, hearing problems, and learning difficulties (Bondy et al., 2007; Pinsker, 2012). Moreover, it is feasible to diminish the risk of infertility in some individuals by cryopreserving oocytes while follicles are still viable (Kavoussi et al., 2008; Borgstrom et al., 2009).

The dosage reduction of genes located in PARs1 and 2, which is inherent to the complete or partial loss of the second sex chromosome, can be sensitively quantified by quantitative polymerase chain reaction (qPCR), as reported for the ARSE gene in Xp22.33 (Rocha et al., 2010).

The aim of the present study was to determine the dosage of two genes located in the pseudoautosomal regions (shortstature homeobox $[S H O X]$ and vesicle-associated membrane protein 7 [VAMP7]), two X-specific genes (ubiquitin-like modifier activating enzyme 1 [UBAI] in $\mathrm{p}$, and $\mathrm{X}$ inactivespecific transcript $[X I S T]$ in $\mathrm{q}$ ), the sex determining region $\mathrm{Y}$ (SRY) gene by qPCR in TS patients, and to compare the results to those for the gene dosage of men and women with a

\footnotetext{
${ }^{1}$ Departamento de Genética, Hospital Universitario “Dr. José Eleuterio González,’ Universidad Autónoma de Nuevo León, Monterrey, Nuevo León, México.

${ }^{2}$ Facultad de Enfermería, Universidad Autónoma de Nuevo León, Monterrey, Nuevo León, México.
} 
normal karyotype. These findings were used to evaluate the effectiveness of these measurements as an affordable method for TS screening.

\section{Materials and Methods}

\section{Population}

We performed a descriptive, comparative, nonblinded study that included 27 TS patients who were karyotyped between 2005 and 2012 by the Genetics Department, University Hospital, "Dr. Jose E González" of the Universidad Autónoma of Nuevo León in Monterrey, México. Volunteer subjects with a normal karyotype (10 females and 10 males) were recruited from the same institution and used as controls. Written informed consent was obtained from all subjects or legal guardians, and the Health Research Ethics Board of the UANL Medical School approved the study (Approval No.: GN-11-004).

The subjects were divided into four groups according to their karyotype: (a) 45,X (X monosomy); (b) 46,XY (male); (c) 46,XX (female); and (d) TS variants (mosaicism and structural aberrations).

\section{Sample collection}

Biological blood samples. Four milliliters of peripheral venous blood was collected in a heparin-treated tube from

Table 1. Relative Quantification Results for the SHOX, XIST, VAMP7, SRY, UBA1 Genes

\begin{tabular}{|c|c|c|c|c|c|c|}
\hline Case & Karyotype & RQ SHOX & RQ XIST & RQ VAMP7 & RQ SRY & RQ UBA1 \\
\hline 1 & $45, X$ & 0.531 & 0.474 & 0.537 & 0 & 0.559 \\
\hline 2 & $45, X$ & 0.571 & 0.501 & 0.491 & 0 & 0.502 \\
\hline 3 & $45, X$ & 0.532 & 0.561 & 0.609 & 0 & 0.462 \\
\hline 4 & $45, X$ & 0.572 & 0.38 & 0.47 & 0 & 0.649 \\
\hline 5 & $45, X$ & 0.505 & 0.462 & 0.451 & 0 & 0.521 \\
\hline 6 & $45, X$ & 0.556 & 0.513 & 0.609 & 0 & 0.564 \\
\hline 7 & $45, X$ & 0.494 & 0.549 & 0.531 & 0 & 0.519 \\
\hline 8 & $45, X$ & 0.545 & 0.512 & 0.534 & 0 & 0.508 \\
\hline 9 & $45, X$ & 0.479 & 0.51 & 0.525 & 0 & 0.513 \\
\hline 10 & $45, X$ & 0.624 & 0.638 & 0.637 & 0 & 0.46 \\
\hline 11 & $45, X$ & 0.472 & 0.516 & 0.645 & 0 & 0.53 \\
\hline 12 & $45, X$ & 0.518 & 0.421 & 0.492 & 0 & 0.722 \\
\hline 13 & 45,X,inv (7)(q31.2-pter) & 0.509 & 0.515 & 0.479 & 0 & 0.537 \\
\hline 14 & $45, X[6] / 46, X X[24]$ & 1.169 & 0.733 & 0.479 & 0 & 0.824 \\
\hline 15 & $45, X[2] / 46, X X[28]$ & 0.8 & 0.871 & 0.777 & 0 & 1.602 \\
\hline 16 & $45, \mathrm{X}[18] / 46, \mathrm{XX}[12]$ & 0.623 & 0.605 & 0.629 & 0 & 0.611 \\
\hline 17 & $45, X[12] / 46, X X[18]$ & 0.535 & 0.718 & 0.761 & 0 & 0.533 \\
\hline 18 & $45, \mathrm{X}[13] / 46, \mathrm{XX}[7]$ & 0.59 & 0.689 & 0.711 & 0 & 0.702 \\
\hline 19 & $45, X[6] / 47, X X X[24]$ & 1.016 & 1.108 & 1.084 & 0 & 1.079 \\
\hline 20 & $45, X[10] / 49, X X X X[3] / 46, X X[86]$ & 0.99 & 0.906 & 0.899 & 0 & 1.034 \\
\hline 21 & $45, X[6] / 47, X X X[24]$ & 0.703 & 0.63 & 0.616 & 0 & 0.762 \\
\hline 22 & $45, X[20] / 46, X Y[10]$ & 0.809 & 0.509 & 0.792 & 0.561 & 0.542 \\
\hline 23 & $45, \mathrm{X}[17] / 46, \mathrm{XY}[3]$ & 0.859 & 0.484 & 0.458 & 1.784 & 0.549 \\
\hline 24 & $45, \mathrm{X}[17] / 46, \mathrm{X}, \mathrm{r}[13]$ & 0.506 & 0.688 & 0.473 & 0 & 0.694 \\
\hline 25 & $45, \mathrm{X}[5] / 46, \mathrm{X}, \mathrm{i}(\mathrm{X})(\mathrm{q} 10)[25]$ & 0.53 & 1.053 & 1.146 & 0 & 0.514 \\
\hline 26 & $45, \mathrm{X}[\mathrm{b}] / 46, \mathrm{X}, \mathrm{i}(\mathrm{X})(\mathrm{q} 10)[24]$ & 0.527 & 1.012 & 1.097 & 0 & 0.558 \\
\hline 27 & $46, X, i(X)(\mathrm{q} 10)$ & 0.5 & 1.026 & 1.535 & 0 & 0.973 \\
\hline 28 & $46, X X$ & 1 & 1.062 & 1.083 & 0 & 1.012 \\
\hline 29 & $46, X X$ & 1 & 1 & 1 & 0 & 1 \\
\hline 30 & $46, X X$ & 1 & 1 & 1 & 0 & 1 \\
\hline 31 & $46, X X$ & 1 & 1 & 1 & 0 & 1 \\
\hline 32 & $46, X X$ & 1 & 1 & 1 & 0 & 1 \\
\hline 33 & $46, X X$ & 0.908 & 1.111 & 1.039 & 0 & 0.999 \\
\hline 34 & $46, X X$ & 1 & 1 & 1 & 0 & 1 \\
\hline 35 & $46, X X$ & 1 & 1 & 1 & 0 & 1 \\
\hline 36 & $46, X X$ & 1 & 1 & 1 & 0 & 1 \\
\hline 37 & $46, X X$ & 1 & 1 & 1 & 0 & 1 \\
\hline 38 & $46, X Y$ & 1.069 & 0.513 & 1.127 & 0 & 0.536 \\
\hline 39 & $46, X Y$ & 0.952 & 0.56 & 1.105 & 2.737 & 0.533 \\
\hline 40 & $46, X Y$ & 1.025 & 0.561 & 1.103 & 0 & 0.548 \\
\hline 41 & $46, X Y$ & 1.052 & 0.558 & 1.613 & 0 & 0.495 \\
\hline 42 & $46, X Y$ & 0.994 & 0.491 & 0.971 & 0 & 0.507 \\
\hline 43 & $46, X Y$ & 0.959 & 0.506 & 1.097 & 3.897 & 0.511 \\
\hline 44 & $46, X Y$ & 1.005 & 0.487 & 1.104 & 0 & 0.524 \\
\hline 45 & $46, X Y$ & 0.981 & 0.472 & 1.016 & 0 & 0.552 \\
\hline 46 & $46, X Y$ & 1.053 & 0.488 & 0.999 & 0 & 0.547 \\
\hline 47 & $46, X Y$ & 1.169 & 0.512 & 1.164 & 1.007 & 1.042 \\
\hline
\end{tabular}

RQ, relative quantification. 
each participant for G-banding karyotype (Barch et al., 1997) in our laboratory, which is accredited by the College of American Pathologists (CAP). Only four patients and the control subjects were karyotyped during this study. Twenty-three patients who had been previously karyotyped and diagnosed with TS were invited to participate, and a 4-mL blood sample was collected in EDTA tubes to obtain total genomic DNA. Extraction was conducted using an automated QIAcube ${ }^{\circledR}$ instrument and QIAamp ${ }^{\circledR}$ DNA Mini and Blood Mini Extraction Kits (Qiagen, Valencia, CA).

Gene selection. Five probe-on-demand assays (Applied Biosystems, Foster City, CA) were used to measure the dosage of five genes: SHOX at PAR1, VAMP7 at PAR2, $U B A 1$ at Xp11.23, XIST at Xq13.2, and $S R Y$ at Yp11.3 (Table $1)$. The RNase $P$ gene was used as an autosomal reference control.

Real-time PCR analysis. The dosage of each gene was measured with the StepOnePlus ${ }^{\mathrm{TM}}$ System (Applied Biosystems) and TaqMan Genotyping Master Mix 2X (Applied Biosystems) following the manufacturer's instructions. Relative quantification $(\mathrm{RQ})$ values were obtained using the Delta CT comparison method $\left(\Delta \Delta \mathrm{C}_{\mathrm{T}}\right)$ (Livak and Schmittgen, 2001). Amplification reactions were performed in triplicate with determined reproducibility. In TS patients, an RQ $<1$ for SHOX and VAMP7 was expected.
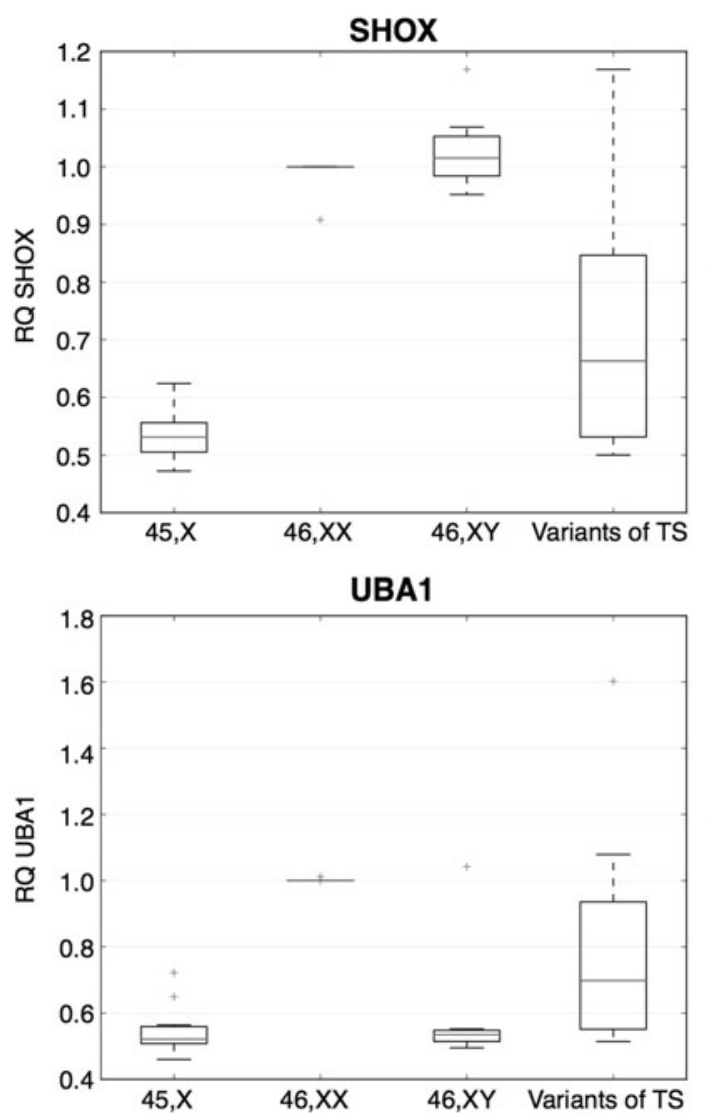

\section{Statistical analysis}

Descriptive statistics were applied to the RQ values of each gene. ANOVA was used to analyze intergroup differences between gene dosages, which were determined by the mean RQ values of each gene. Differences were considered statistically significant when the $p$-value was $<0.05$.

\section{Results}

Of the 47 samples, 20 were from the control group (10 $46, \mathrm{XY}$ and $1046, \mathrm{XX})$ and 27 from TS patients. Among the latter, 13 (48\%) had monosomy $\mathrm{X}$ and 14 had a TS variant, with 45,X/46,XX mosaicism being the most frequent (19\%) karyotype (Table 1).

The RQ value of the SHOX gene in patients with TS ranged from 0.50 (minimum) to 0.85 (maximum) and it ranged from 0.97 to 1.07 in the control group (Table 1). The VAMP7 gene presented an RQ range from 0.47 to 0.57 in patients diagnosed with complete $\mathrm{X}$ monosomy (Table 1 ) and from 0.57 to 0.99 for the TS chromosomal variants. The RQ values from the control group ranged from 0.99 to 1.25 . The RQ values for the $X I S T$ gene in the patients with complete $\mathrm{X}$ monosomy ranged from 0.46 to 0.54 and from 0.66 to 0.90 in the TS variant group. In contrast to the patients, the RQ for the control group ranged from 0.98 to 1.04 in female subjects with a $46, \mathrm{XX}$ karyotype and from 0.49 to 0.53 in males with a $46, X Y$ karyotype (Table 1). In the case of the UBAl gene, the RQ in patients with complete $\mathrm{X}$ monosomy was from 0.49 to 0.58 ,

FIG. 1. Box and whisker plot of relative quantification (RQ) results from the four groups evaluated. 
and in the TS variant group, the RQ values ranged from 0.60 to 0.95 . The control group RQ range for the same gene was from 0.99 to 1.00 for $46, \mathrm{XX}$ and from 0.46 to 0.69 for $46, \mathrm{XY}$. The $S R Y$ gene RQ in patients with complete $\mathrm{X}$ monosomy was 0.0 , ranging from 0.47 to 0.66 in the TS variant group. For the controls, the RQ for the $S R Y$ gene was 0.0 in the $46, \mathrm{XX}$ female subjects and from 0.97 to 1.09 in male $46, \mathrm{XY}$ subjects.

The ANOVA showed significant differences $(p<0.05)$ in the gene dosage for SHOX, XIST, UBA1, and VAMP7 between the study groups and the controls. The most useful markers for the TS variant group (mosaicism and structural aberration) were those found in PAR1 and PAR2 and SHOX and VAMP7, which showed more consistent results and a greater ability to discern between the TS patients versus controls (Fig. 1).

In the descriptive analysis, the RQ ranges of $S H O X$ and $V A M P 7$ obtained from the TS groups showed a difference of more than \pm 3 standard deviation from that of the control group. The RQ cutoff was established at 0.8 , with a sensitivity and a specificity of $100 \%$ in patients with complete monosomy $X$ and a sensitivity of $64 \%$ and a specificity of $100 \%$ for the TS variants. If we analyzed mosaic TS $(45, \mathrm{X} / 46, \mathrm{XX})$ only, the sensitivity lowers to $83 \%$ and to $64 \%$ in TS variants.

All of the gene markers in patients with different chromosomal variants were evaluated to analyze whether the chromosomal formula could be identified without a conventional karyotype. Using individuals with a 46,XX karyotype as a reference, a difference between the gene dose of $X I S T$ and UBAl was found; however, when compared to $46, X Y$ individuals, who are hemizygous for these genes, the RQ was similar to that found in most patients with TS. Thus, the RQ for XIST and UBAI was not considered to be useful for analysis and diagnosis (Fig. 1). The $S R Y$ gene is only of qualitative utility because it identifies individuals with a $46, \mathrm{XY}$ chromosomal formula.

\section{Discussion}

Early diagnosis of TS leads to proper treatment of complications and can aid in avoiding or reducing deleterious consequences in adult life. The frequent delay in the diagnosis of TS justifies the search for methodologies that allow prompt diagnosis of partial or complete, homogeneous or mosaic, and $\mathrm{X}$ chromosome monosomy. In the present study, we analyzed 27 patients with TS to determine the gene dosage of SHOX, VAMP7, XIST, UBA1, SRY, and RNase $P$ in 47 individuals. The group with complete monosomy $X$ represented $48 \%$ of all samples in the study group. Of the remaining TS patients, $19 \%$ were mosaic with $45, \mathrm{X} / 46, \mathrm{XX}$, followed by other mosaics and structural aberrations present in similar proportions to those reported in the literature (Sybert and McCauley, 2004).

In our study, the differences between RQ means in the patients with complete monosomy and control subjects were significantly different. Similar findings have been reported by Rocha et al. (2010).

Overall, the patients had half of the dosage (compared to $46, \mathrm{XX}$ women) in all X chromosome genes analyzed and the absence of the $S R Y$ gene. If the analysis of the studied genes is used as a screening test in a population, it will differentiate between individuals with a 46,XY karyotype and TS patients. Detection of the $S R Y$ gene is considered of great importance in patients with mosaic forms of TS (Coto et al., 1995; Mendes et al., 1999; Gravholt et al., 2000). The analysis of the RQ for the $S R Y$ gene in the present study will permit the detection of variants of TS with the presence of a Y chromosome (this occurs in 3-5\% of TS cases), which increases the risk for gonadal tumors, especially gonadoblastoma (Osipova et al., 1998). Therefore, we believe that including this gene $(S R Y)$ in our analysis provides a more useful tool for the study of patients with TS.

Patients with mosaic 45,X/46,XY had a decreased RQ for SHOX and VAMP7 compared to normal males (46,XY).

Differences in the mean RQ values observed in samples with chromosomal variants were not as clear-cut, especially in the case of mosaics with a $45, \mathrm{X}$ clone present below $20 \%$ (cases 14 and 20) and in mosaics with polysomy X (e.g., case 19) that presented an $R Q \geq 1$. We think that the extra $X$ chromosome compensates for the monosomy $\mathrm{X}$ in other cells. As expected, the most evident gene dosage alterations were observed in SHOX and VAMP7, which thereby appear to be reliable and useful markers in diagnosing TS (Fig. 1). Detection sensitivity for the different TS variants altogether was $64 \%$, but when only mosaic forms were analyzed $(45, \mathrm{X} /$ $46, \mathrm{XX})$, sensitivity increased up to $83 \%$. It is important to mention that this genotype is the second most common after monosomy (Sybert and McCauley, 2004; Davenport, 2010).

Despite the low number of participants - a limitation of our study that should be addressed to increase the statistical power - the use of qPCR to determine the dosage of SHOX and $V A M P 7$ appears to be a useful, quick, and affordable neonatal screening test in infants with clinical suspicion of TS.

The delay in TS diagnosis is a problem, and methodologies that allow early diagnosis of patients, including those with chromosomal variants, are needed. Guidelines of the American College of Endocrinology for the management of patients with TS have addressed the potential benefit of designing a newborn screening method for the detection of these patients (Bondy et al., 2007). We propose the quantification of the gene dose of $S H O X$ and $V A M P 7$ as a screening tool for the diagnosis of newborns with TS.

\section{Author Disclosure Statement}

No competing financial interests exist.

\section{References}

Barch MJ, Knutsen T, Spurbeck JL (1997) The AGT Cytogenetics Laboratory Manual. 3rd ed. Lippincott Williams and Wilkins, Philadelphia.

Bianchi I, Lleo A, Gershwin ME, Invernizzi P (2012) The X chromosome and immune associated genes. J Autoimmun 38:J187-J192.

Bondy CA, Turner Syndrome Study Group (2007) Care of girls and women with Turner syndrome: a guideline of the Turner Syndrome Study Group. J Clin Endocrinol Metab 92:10-25.

Borgstrom B, Hreinsson J, et al. (2009) Fertility preservation in girls with Turner syndrome: prognostic signs of the presence of ovarian follicles. J Clin Endocrinol Metab 94:74-80.

Coto E, Toral JF, Menendez MJ, et al. (1995) PCR-based study of the presence of Y-chromosome sequences in patients with Ullrich-Turner syndrome. Am J Med Genet 3:393-396.

Davenport ML (2010) Approach to the Patient with Turner Syndrome. J Clin Endocrinol Metab 95:1487-1495.

Ford CE, Jones KW, et al. (1959) A sex-chromosome anomaly in a case of gonadal dysgenesis (Turner's syndrome). Lancet 1:711-713. 
Gravholt CH, Fedder J, Naeraa RW, et al. (2000) Occurrence of gonadoblastoma in females with Turner syndrome and $\mathrm{Y}$ chromosome material: a population study. J Clin Endocrinol Metab 9:3199-202.

Kavoussi SK, Fisseha S, et al. (2008) Oocyte cryopreservation in a woman with mosaic Turner syndrome: a case report. $\mathbf{J}$ Reprod Med 53:223-226.

Li Z, Haines CJ, Han Y (2008) Micro-deletions of the human Y chromosome and their relationship with male infertility. J Genet Genomics 35:193-199.

Livak KJ, Schmittgen TD (2001) Analysis of relative gene expression data using real-time quantitative PCR and the 2(-Delta Delta C(T)) method. Methods 25:402-408.

Mangs A, Morris BJ (2007) The human pseudoautosomal region (PAR): origin, function and future. Curr Genomics 8: 129-136.

Massa G, Verlinde F, et al. (2005) Trends in age at diagnosis of Turner syndrome. Arch Dis Child 90:267-268.

Mendes JR, Strufaldi MW, Delcelo R, et al. (1999) Y-chromosome identification by PCR and gonadal histopathology in Turner's syndrome without overt Y-mosaicism. Clin Endocrinol 1:19-26.

Osipova GR, Karmanov ME, Kozlova SI, et al. (1998) PCR detection of Y-specific sequences in patients with UllrichTurner syndrome: clinical implications and limitations. Am J Med Genet 76:283-287.

Pinsker JE (2012) Clinical review: Turner syndrome: updating the paradigm of clinical care. J Clin Endocrinol Metab 97:E994-E1003.
Ranke MB, Saenger P (2001) Turner's syndrome. Lancet 358: 309-314.

Rocha MN, Longui CA, et al. (2010) Applicability of real-time PCR methodology in the neonatal detection of Turner syndrome. Horm Metab Res 42:677-681.

Stochholm K, Juul S, et al. (2006) Prevalence, incidence, diagnostic delay, and mortality in Turner syndrome. J Clin Endocrinol Metab 91:3897-3902.

Sybert VP, McCauley E (2004) Turner's syndrome. N Engl J Med 351:1227-1238.

Wiedemann HR, Glatzl J (1991) Follow-up of Ullrich's original patient with "Ullrich-Turner" syndrome. Am J Med Genet 41:134-136.

Zhong Q, Layman LC (2012) Genetic considerations in the patient with Turner syndrome-45, X with or without mosaicism. Fertil Steril 98:775-779.

Address correspondence to:

Marisol Ibarra-Ramírez, MD

Departamento de Genética

Hospital Universitario "Dr. José Eleuterio González" Universidad Autónoma de Nuevo León Av. Gonzalitos $s / n$ Colonia Mitras Centro Monterrey, NL 64460

México

E-mail: m.ibarrar25@gmail.com 